\title{
ASLI 2018
}

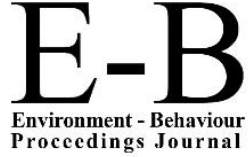

\section{AicQoL2018PerhentianIsland \\ http://www.amerabra.org; $h$ ttps://fspu.uitm.edu.my/cebs $6^{\text {th }}$ AMER International Conference on Quality of Life \\ Pulau Perhentian Resort, Malaysia, 03-04 March 2018 \\ "Quality of Life in the Built \& Natural Environment 6"}

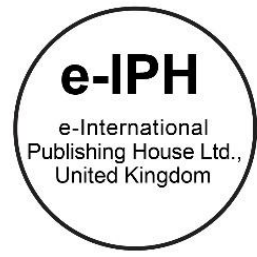

\section{Packaging Development for Promotion Dam Tourism Community: Ratchaprapa Dam, Khaosok National Park, Surat Thani Province}

\author{
Sarath Simsiri1 ${ }^{1}$, Ratananaphadol Smitinand ${ }^{2}$, Mana Eiambua ${ }^{3}$ \\ ${ }^{1}$ Ph.D., Lecturer, ${ }^{2}$ Lecturer, ${ }^{3}$ Asst. Prof., \\ School of Tourism and Hospitality, \\ Suan Dusit University, Thailand. \\ sarath308@hotmail.com
}

\begin{abstract}
The study of Product and Packaging factors that Influence on Consumer Purchase Decision aims to study consumers' products demands inclusive of the factors affecting consumer interest and buying decisions and explores the characteristics of packaging that is consistent with consumer demand and to offer product and packaging design guideline which can attract and make consumer purchasing decisions. The study reveals consumers prefer local products, fine-looking packages which reasonable price, can use as a souvenir, geometric shape packaging are the factors affecting consumer interest and purchase decisions. Thus, this could benefit to design and develop products to meet the needs of consumers.
\end{abstract}

Keywords: Packaging; Purchasing decisions; Tourism; Ratchaprapa Dam

eISSN: 2398-4287@ 2018. The Authors. Published for AMER ABRA cE-Bs by e-International Publishing House, Ltd., UK. This is an open access article under the CC BYNC-ND license (http://creativecommons.org/licenses/by-nc-nd/4.0). Peer-review under responsibility of AMER (Association of Malaysian Environment-Behaviour Researchers), ABRA (Association of Behavioural Researchers on Asians) and cE-Bs (Centre for Environment-Behaviour Studies), Faculty of Architecture, Planning \& Surveying, Universiti Teknologi MARA, Malaysia.

DOI: https://doi.org/10.21834/e-bpj.v3i7.1280

\subsection{Introduction}

Visiting a dam as a tourist destination is rapidly growing trend among Thai tourists especially Ratchaprapa Dam, located in Khaosok National Park, Surat Thani province in the south of Thailand. There are more than 250,000 tourists who travel to Ratchaprapa Dam each year And the trend of tourists is continue to grow yearly. (Department of National Parks, Wildlife and Plant Conservation, 2016). The variety of tourism activities is still one of the most important factors to attract tourists to the destination. At the same time buying souvenir is one of the tourist activities which postulates the attributes to the destination (Goeldner et al., 2000). Buying a local souvenir can provide a destination's authenticity to tourists in some way since distinctive features of the destination are usually part of souvenirs (Revilla and Godd, 2003). Mostly, souvenirs are produced from local ingredients, features and craftsmen which different purposes of use and type (Hume, 2009) for example appliances, accessories or decorations which can be divided into 5 categories as follow: (1) picture, postcard, and book (2) local ingredients (3) model (4) message and (5) local product. Hence a local souvenir could represent an identity, creativity and beauty which reflects culture and tradition of a destination (Gordon, 1986; Fairhurst et al., 2007). Despite the representation of the destination in term of image and attraction of the local products, they can generate income to the community, create an impression and remind tourists of the destination (Yupadee, 2001). The study of customer decision making towards product type and packaging help to understand customer perception and satisfaction which will lead to the purchasing process. However, each customer may be different depending on their culture experience and motivation when buying product hence the understanding of the customer needs is vital to the product development process. Nowadays there is a tool used to understand the inside thought of consumer known as Kansei engineering (Nagamachi, 1992 and Simon, 2004) and Black box model which is the process to see the relationship between customer and external stimulation to use information for developing the product (Nalineben, 2013). Customer satisfaction

eISSN: 2398-4287@ 2018. The Authors. Published for AMER ABRA cE-Bs by e-International Publishing House, Ltd., UK. This is an open access article under the CC BYNC-ND license (http://creativecommons.org/licenses/by-nc-nd/4.0/). Peer-review under responsibility of AMER (Association of Malaysian Environment-Behaviour Researchers), ABRA (Association of Behavioural Researchers on Asians) and cE-Bs (Centre for Environment-Behaviour Studies), Faculty of Architecture, Planning \& Surveying, Universiti Teknologi MARA, Malaysia.

DOI: https://doi.org/10.21834/e-bpj.v3i7.1280 
results from individual attributes, emotions and feelings that vary (Huynh et al., 2010). Communicating information to the consumer is also focal to their purchasing decision which related to the idea of interpretation through physical and response in architecture theory (Hershberger, 1970). Under these circumstances, a product's packaging may be a driver of consumer decision making (Woradit, 2003 and Wachira, 2012). Figure and graphic of the product packaging could also convey the value and quality of the product to the customer (Meyers, 1998; Ampuero and Vila, 2006; Ricardo, 2008). Product packaging plays an important role in reflecting image meaning and attribute of the product through the customer decision making in each stage and lastly buying the most appreciated product (Siriwan, 2007). The package development for promoting tourism in Ratchaprapa Dam aims to study the packaging development process. As the researcher believe that the product packaging is an effective marketing tool in term of communicating information and identity of the community and accounts for the main tool in sale as it can lead to customer purchasing decision (Shah, et al., 2013). Tourism promotion packaging, the appearance of face of the package including brand and label should be reflectively stood out for representing the blend of the product and the tourism destination to the tourists. This study has 3 main concepts of creating tourism product package that meet the customers need. First, community identity of Ratchaprapa Dam, the study investigate special characteristics in community and applied them into the package in order to convey value and identity of community to the customers. Second concept is the appearance of product package that influence the tourists' requirement. There are 2 famous product from Ratchaprapa Dam. The first product is a turmeric soap which made from turmeric herb which is claimed to be one of the best herb in the world and is used in many of skincare product. Another product produced from Ratchaprapa Dam is woven which got an inspiration from Queen Sirikit who introduced the knowledge of woven to the community. These 2 products require the good package development that can help in promoting tourism image and increase sale and to be well known among tourists who visit Ratchaprapa Dam. Therefore the study on the package development process is needed in order to find the best suitable package for these 2 products in term of appearance, shape, material, color, graphic which can tell the story of the product. The third concept is the packaging perception and evaluation which is the study of the influence of packaging and customer decision making. The result of this study on packaging development will lead to the customer perception, understanding, liking, satisfaction which finally result in purchasing decision. Apart from a good design of packaging, marketing strategy is also necessary as it is a key that helps in promoting image to customer and encourages them to buy the product (Shah. et al, 2013, Seo and Sundar, 2013). Packaging of product is another tool that lead the customer to product awareness, perception and trust in buying the product (Hawkes, 2010 and Spence, 2016). The package designer should consider the appearance of the package which can connect to the real product inside the package (Spence, 2011 and Ngo. et al, 2012). The product explanation on the package should provide clear and correct information which create the good relationship between the producer and the customer (Jedlicka, 2009).

Product package is play an important role for containing, protecting, transporting and be a marketing tool which reflect image that inform the product attribute and benefit received from using the product. The design of package is the representation of the product image which lead to customer perceived value, building trust and finally buying a product (Becker et al, 2011, Mizutani et al, 2012, Shah. et al, 2013 and Mugge. et al, 2014). This idea is in line with the study by Ricardo (2008) who found shape and color of package can communicate the meaning to the customer for the quality of the product. Moreover, the design such as color, font, picture and the use of the logo: color, text, material, image, shape can speak out of value, and quality of the product (Meyers,1998, McNeal and Ji, 2003, Becker. et al, 2011, Fiszman and Spence, 2011, Fiszman and Spence, 2012, Velasco. et al, 2014 and Velasco. Et al, 2015). The concept of meaning of architecture also help in convey the visualization or presentational meanings which are in form of some identity communication that are a presentational and representational from those visible view. Then the acknowledge of the product benefits are occurred through decoding of visualization of the product and lastly lead to responsive meanings which are the emotional response that reveal in form of the need, desire, accept, reject etc (Noppadol Sahachaiseri, 2003). Normally a person will have the perception process as a set .of behavior that lead to the different responses, Ratakasikorn and Hinchiranan (2008) said perception is the main factor to the meaning of a tangible object. This is based on the process on knowledge, emotion and behavior which will response to a person decision of place or object. So it is necessary to know the need of customers' decision of buy or not to buy the product. This is also depend on personal factor for example gender, nationality, the thinking process, or emotion (Van-Nam Huynh. et al., 2010) as well as social and economic status and political issues which will directly impact the tourist behavior (Littrell et al., 1994 and Park,2000). The factor of product type and packaging is the main focus of this study. The study will also examine the customer perception towards product type and packaging that match their needs and choices. The result of this study will provide the suggestions for product development to promote the tourism industry at Ratchaprapa Dam in Surat Thani Province.

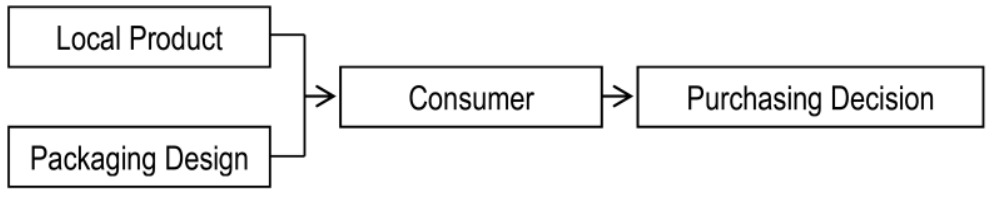

Fig. 1. Conceptual Framework 


\subsection{The Purpose of the Research}

The objective of this paper is to study customer needs and preferences when buying the product, to study different factors that attract the customer interest and purchasing decision, to examine the product attribute that relates to customer needs and to suggest of product development process that will attract the customer interest and lead to the purchasing decision.

\subsection{Research Methodology}

The study applied the quantitative methodology to find a fact, together with the related theoretical framework helped the researcher to target the required population. This study used a survey approach to reach the research objectives. The result would be analyzed through the statistical process to describe and predict the relationship between the variables in the study. This approach will provide the creditability and could be generalized to other related studies.

Regarding the first research objective as to study customer needs and preferences when buying the product was the issue to find the type of product that the tourist who visits the destination would purchase to design the product that matches with their interest. For the second research objective, to study different factors that attract the customer interest and purchasing decision was an aim to discover the key factors of tourists purchasing decision with the high focus on the packaging. The third research objective, as to examine the product attribute that relates to customer needs since it will lead to the sale of the product. Last research objective as to provide the recommendation of product development process that will attract the customer interest and lead to the purchasing decision, this is a research result from the whole study.

This study followed the theoretical framework and proposed methodology used questionnaire technique to achieve the opinions of the product purchasing requirement, the purchasing decision factor, and the type of packaging that meets the customer requirement. Each variable in the questionnaire are from the extensive of literature review and applies the statistical test for the accessibility of analyzing and report the findings in term of decretive analysis. The reliability was tested using a Likert scale to find internal consistency to see the correlate of each question. The coefficient of reliability of the questionnaire was .877 indicated the high level of reliability. There were 282 respondents participated in this study who are Thai tourists. The data were collected at Ratchaprapa Dam, Khaosok National Park, Surat Thani Province using convenience sampling which is the accidental method of sampling depends on the researcher convenient. Therefore, the respondent could be anyone who visit the dam and who were willing to do the questionnaire. The data were statistically analyzed and presented in term of descriptive analysis using frequency and mean to generate the product development process that will match the customer needs.

\subsection{Results}

The majority of respondents were females $(70.9 \%)$ and males $(29.1 \%)$ with an average age of 34 years old. As for the level of education, half of the respondents (49.1\%) were postgraduate, $37.4 \%$ were graduate and, $13.6 \%$ were below graduate with average incomes of 28,000 baht.

From the study of buying choice of the respondents has found that the majority of the respondents were interested in buying local fabric and garment $(51.5 \%)$. Almost half of the respondents (44.3\%) were interested in buying local art and souvenir, $30.5 \%$ of the respondents were interested in buying local food, and $26 \%$ of the respondents were interested in purchasing appliance and accessory, while health product or herb the respondents who are interested in buying were $23.7 \%$, and drinks were $17.5 \%$ accordingly. For purchasing the souvenir, the data show that the respondents were interested in local handmade the most, the second was picture postcard or book and lastly the product that consists name of the destination or model of the place.

The result of factor that contribute to the interest and customer decision making indicated the important of customer thought before purchasing the product as follow (1) a beautiful and attractive packaging (2) reasonable price (3) suitable to buy for others (4) modern and in trend style (5) creating value and good quality (6) destination representative (7) collectible (8) suitable for decoration item (9) usable (10) compact (11) standard qualified (12) original and authentic and (13) special and limited. See Table 1.

The findings of the packaging attributions that relate to customer needs and preferences has found that the majority of respondents pay attention to synthetic materials of packaging, the second attribute was the harmonious of color of the packaging, the third attribute was the level of the depth of the color, next attribute was colorfulness of the packaging which was color in the same tone, color in sepia, less variety of color and more variety of color accordingly. The fifth attribute was surface which was matted surface, embossed surface, smooth surface, and glossy surface respectively. The sixth attribute was the display. The respondents gave attention highly to the display of the product on the package or illustration of the product on the package which should be a realistic one. The last attribute was shaped which was geometry, polygons, freeform, and natural imitation respectively. See Table 2.

The findings on the product packaging utilities indicated that the respondents found the representative of product identity was the most important factor. The minor factors were the representative of local identity, carry capability, value-added, display of real product, display of product information, protection, product storage after opening, product lifecycle, wrapping, and recycling respectively. See Table 3. 
Table 1. Factors affecting interest and purchasing decision.

\begin{tabular}{clcc}
\hline No. & \multicolumn{1}{c}{ Item } & Mean & S.D. \\
\hline 1 & A beautiful and attractive packaging & 4.23 & .68 \\
2 & Reasonable price & 4.14 & .77 \\
3 & Suitable to buy for others & 4.07 & .84 \\
4 & Modern and in trend style & 3.96 & .85 \\
& Creating value & 3.92 & .79 \\
5 & Good quality & 3.86 & .80 \\
6 & Destination representative & 3.85 & .84 \\
7 & Collectible & 3.83 & .75 \\
8 & Suitable for decoration item & 3.77 & .86 \\
9 & Usable & 3.75 & .82 \\
10 & Compact & 3.72 & .88 \\
11 & Standard qualified & 3.64 & .90 \\
12 & Original and authentic & 3.61 & .79 \\
13 & Special and limited & &
\end{tabular}

Table 2. Features used in packaging design.

\begin{tabular}{|c|c|c|c|}
\hline & Item & Mean & S.D. \\
\hline \multirow[t]{3}{*}{ 1. Materials } & 1. Synthetic materials & 3.73 & .96 \\
\hline & 2. Natural and synthetic materials & 3.50 & .95 \\
\hline & 3. Natural materials & 3.16 & .89 \\
\hline \multirow[t]{2}{*}{ 2. Colour type } & 1. Harmony & 3.96 & .80 \\
\hline & 2. Contrast & 3.56 & .86 \\
\hline \multirow[t]{3}{*}{ 3. Color intensity } & 1. Hight & 3.84 & .88 \\
\hline & 2. Medium & 3.63 & .96 \\
\hline & 3. Low & 3.29 & .90 \\
\hline \multirow[t]{4}{*}{ 4. Colour tone } & 1. Mono tone & 3.80 & .80 \\
\hline & 2. Sepia & 3.79 & .93 \\
\hline & 3. Less color & 3.67 & .88 \\
\hline & 4. Various colors & 3.50 & .96 \\
\hline \multirow[t]{4}{*}{ 5. Texture } & 1. Rough & 3.91 & .79 \\
\hline & 2. Convex & 3.75 & .88 \\
\hline & 3. Smooth & 3.72 & .79 \\
\hline & 4. Luster & 3.58 & .99 \\
\hline \multirow[t]{2}{*}{ 6. Display } & 1. Drill the channel & 3.96 & .87 \\
\hline & 2. Use illustrations & 3.53 & .88 \\
\hline \multirow[t]{2}{*}{ 7. Picture } & 1. Reality & 3.54 & .95 \\
\hline & 2. Abstract & 3.46 & .95 \\
\hline \multirow[t]{4}{*}{ 8. Shape } & 1. Geometry & 3.85 & .91 \\
\hline & 2. Polygonal geometry & 3.71 & .72 \\
\hline & 3. Free shape & 3.62 & .99 \\
\hline & 4. Imitation & 3.54 & 1.06 \\
\hline \multicolumn{4}{|c|}{ (Source: Sarath SIMSIRI) } \\
\hline \multicolumn{4}{|c|}{ Table 3. Benefits of packaging. } \\
\hline No. & Item & Mean & S.D. \\
\hline 1 & Representative of product identity & 4.14 & .80 \\
\hline 2 & Representative of local identity & 4.12 & .81 \\
\hline \multirow[b]{2}{*}{3} & Carry capability & & .86 \\
\hline & Value-added & 4.00 & .78 \\
\hline 4 & Display of real product & 3.98 & .86 \\
\hline 5 & Display of product information & 3.95 & .78 \\
\hline 6 & Product protection & 3.88 & .80 \\
\hline 7 & Product storage after opening & 3.87 & .86 \\
\hline 8 & Product lifecycle & 3.86 & .75 \\
\hline 9 & Product wrapping & 3.81 & .88 \\
\hline 10 & Recycling respectively & 3.73 & .90 \\
\hline
\end{tabular}

(Source: Sarath SIMSIRI) 


\subsection{Discussion and Conclusion}

Buyer's purchase decision is starting from internal need or external stimulus, information search from experience or environment to evaluate the alternative and finally purchasing the most likeable to the product (Siriwan, 2007). The findings of this study indicated the suggestion of product development process that will attract the customer interest and lead to the purchasing decision in 3 issues following the research objectives which would fulfil the marketing process and strategy to achieve the customer satisfaction and market objectives (Seri, 1999). The results would also provide the understanding and predict the consumer behaviour and know their needs and attitudes to stimulate the acceptance of the product (Schiffman and Kanuk, 2000).

The product that would meet the needs of the customer should firstly focus on the local handmade product such as fabric, garment, art, appliance, decoration since these are the most interesting product to the customer. The minor interested products were the picture, postcard and book. Whereas the other types of product such as local souvenir with the name of the place, identity product, food, accessory, health product or herb, and drink could be sold at the destination since there was still some interest from the customer. Another key factor to attract the customer interest and would affect the customer buying decision were well-designed packaging and reasonable price souvenir as well as the modern and representation of the destination of the product.

For the product attribute, the customers were paying high attention to the shape, the making of product which was synthetic materials and the use of harmonious colour with the same tone, matte surface, product display and realistic product illustration. Lastly, the packaging should indicate the local identity and easy to carry. see Table 4.

\begin{tabular}{|c|c|c|c|}
\hline & Stimulus & Item & Response \\
\hline \multirow[t]{3}{*}{1.} & Product & 1. cloth or costume & \\
\hline & & 2. Art & \\
\hline & & 3. Craft & \\
\hline \multirow[t]{3}{*}{2.} & Product attribute & 1. Beautiful packaging & \\
\hline & & 2. Reasonable price & \\
\hline & & 3. suitable to buy for others & \\
\hline \multirow[t]{11}{*}{3.} & Packaging & 1. Geometry & Interested in product and \\
\hline & & 2. Synthetic materials & making purchase decision \\
\hline & & 3. Harmony colour & \\
\hline & & 4. Hight color intensity & \\
\hline & & 5. Mono tone & \\
\hline & & 6. Rough texture & \\
\hline & & 7. Drill the channel & \\
\hline & & 8. Realistic picture & \\
\hline & & 9. Representative of product identity & \\
\hline & & 10. Representative of local identity & \\
\hline & & 11. Carry capability & \\
\hline
\end{tabular}

(Source: Sarath SIMSIRI)

\subsection{Suggestions}

This study used only quantitative approach and the data collection process was at specific tourist destination hence the results would be varied depending on the different population. The findings would only apply in this context.

The future research should examine the different on the race, gender, age, occupation and travelling pattern towards the product buying decision making to generate the product and packaging development process which will extensively meet the customer needs and preferences.

\section{Acknowledgements}

The completion of this research could not have been possible without the participation and assistance of so many people. First of all, we are grateful to National Research Council of Thailand who granted the research scholarship and was the knowledge dissemination to the related and interested people. We take this opportunity to record our sincere thanks to Suan Dusit University for the support. We place on record, sincere gratitude to the local community, all contributors, all respondents, and to one and all who directly or indirectly have lent their helping hand in this study. Last but not least, we would like to express our gratitude to our team for advisory, encouragement, support, and being a good team member for the success of this research. The researcher would also like to thank the $6^{\text {th }}$ AicQoL2018Perhentianlsland shall be organised by AMER (Association of Malaysian Environment-Behaviour Researchers) and cEBs (Centre for Environment-Behaviour Studies, FSPU, UiTM, Malaysia) that give an opportunity to present this result which is one of the contribution of the research success.

\section{References}


Becker, L., van Rompay, T. J. L., Schifferstein, H. N. J., \& Galetzka, M. (2011). Tough package, strong taste: The influence of packaging design on taste impressions and product evaluations. Food Quality and Preference, 22(1), 17-23.

Bix, L., Seo, W., \& Sundar, R. P. (2013). The effect of colour contrast on consumers' attentive behaviours and perception of fresh produce. Packaging Technology and Science, 26(2), 96-104.

Department of National Parks, Wildlife and Plant Conservation, [online] http://www.dnp.go.th/NPRD/develop/data/stat58/fthai_58.pdf

Fairhurst, A., C. Costello, and A. F. Holmes. (2007). An Examination of Shopping Behavior of Visitors to Tennessee According to Tourist Typologies. Journal of Vacation Marketing 13 (4); 311-20.

Goeldner, C. R., Ritchie, J. R. B. \& Mclntosh, R. W. (2000). Tourism. Principles, Practices, Philosophies, New York: John Wiley \& Sons, Inc.

Gordon, B. (1986). The Souvenir: Messenger of the Extraordinary. Journal of Popular Culture 20 (3);135-46.

Hawkes, C. (2010). Food packaging: The medium is the message. Public Health Nutrition, 13(2), 297-299.

HUME, D.L. (2009). The Development of Tourist Art and Souvenirs - The Arc of the Boomerang: From Hunting, Fighting and Ceremony to Tourist Souvenir. International Journal of Tourism Research 11(1): 55-70.

James U. McNeal, Mindy F. Ji, (2003), Children's visual memory of packaging, Journal of Consumer Marketing, Vol. 20No. 5, pp. 400-427.

Leon G. Schiffman, Leslie Lazar Kanuk. (2000). Consumer Behavior. Prentice-Hall, Inc.

Littrell, M. A., S. Baizerman, R. Kean, S. Gahring, S. Niemeyer, R. Reilly, J. Stout. 1994. Souvenirs and Tourism Styles. Journal of Travel Research 33 (1), 3-11.

M.Meyers, H. \& J.Lubliner, M. (1998). Marketer's guide to successful package design. Illinois: NTC Business books.

Meyers, H., and J. Lubliner. )1998(. Marketer's Guide to Successful Package Design. NTC Business Books.

Mizutani, N., Dan, I., Kyutoku, Y., Tsuzuki, D., Clowney, L., Kusakabe, Y., et al. (2012). Package images modulate flavors in memory: Incidental learning of fruit juice flavors. Food Quality and Preference, 24(1), 92-98.

Mugge, R., Massink, T., Hultink, E.-J., \& van den Berg-Weitzel, L. (2014). Designing a premium package: Some guidelines for designers and marketers. The Design Journal, 17(4), 583-605.

Nagamachi, M., Lokman, A.M., (2009). Innovations of Kansei Engineering. Industrial Innovation Series. Adedeji B. Badiru (Eds.). In print, Taylor \& Francis.

Naliniben M. Chauhan. (2013). Consumer Behaviour and his Decision of Purchase. International Journal for Research in Management and Pharmacy (IJRMP). Vol. 2, Issue 5 pp. $1-4$

Ngo, M. K., Piqueras-Fiszman, B., \& Spence, C. (2012). On the colour and shape of still and sparkling water: Insights from online and laboratory-based testing. Food Quality and Preference, 24, 260-268.

Nopadon Sahachaisaeree. (2003). Environment \& Behavior, Urban and Environmental Planning. KMITL.

Park, M. K. (2000). Social and Cultural Factors Influencing Tourists' Souvenir-Purchasing Behavior: A Comparative Study on Japanese 'Omiyage' and Korean 'Sunmul.' Journal of Travel \& Tourism Marketing 9 (1/2), 81-91.

Revilla, G., and T. H. Godd. (2003). Authenticity Perceptions of Talavera Pottery. Journal of Travel Research 42 (1); $94-9$.

Ricardo Pires Goncalves. (2008). Product Characteristics and Quality Perception. Consumer Behavior.

Sabeehullah Shah, Adnan Ahmad and Nawaz Ahmad. (2013). Role of Packaging in Consumer Buying Behavior. International Review of Basic and Applied Sciences 1(2), $35-41$.

Sangarun, Ratakasikorn and Nij Hinchiranan. 2008. Laksana Thai (Thai Characters). Bangkok: Amarin Printing \& Publishing.

Seri, W.,) 1999 .(Consumer Behavior Analysis .Bangkok: Tera Film and Sitex, Inc.

Simon T. W. Schütte. (2004). Concepts, Methods and Tools in Kansei Engineering. Ergonomics Science, Linköpings Universitet, Sweden.

Siriwan, S.,) 2007 .(Marketing strategies \& market oriented strategic management. Bangkok: Thanatut, Inc.

Spence, C. (2011). Crossmodal correspondences: A tutorial review. Attention, Perception, \& Psychophysics, 73, 971-995.

Spence, C. (2016). Multisensory packaging design: Colour, shape, texture, sound, and smell. In M. Chen \& P. Burgess (Eds.), Integrating the packaging and product experience: A route to consumer satisfaction, 1-22.

Van-Nam Huynh, Hongbin Yan, and Yoshiteru Nakamori. (2010). "A Target-Based Decision-Making Approach to Consumer-Oriented Evaluation Model for Japanese Traditional Crafts." IEEE Trans. Eng. Manag 57 (4). 


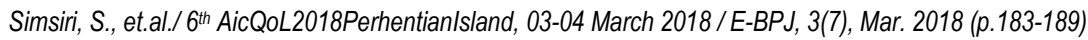

Velasco, C., Salgado-Montejo, A., Marmolejo-Ramos, F., \& Spence, C. (2014). Predictive packaging design: Tasting shapes, typographies, names, and sounds. Food Quality \& Preference, 34, 88-95.

Velasco, C., Woods, A. T., Hyndman, S., \& Spence, C. (2015). The taste of typeface. i-Perception, 6(4), 1-10.

W. Jedlicka. (2009), Packaging Sustainability Tools, Systems and Strategies for Innovative Package Design. USA, John Wiley and sons.

Wachira, W., (2012). Development of Kha Nom Kong Packaging in Nong Kae Sub-Distric, Mueang Uthaithani District

Woradit, K.,) 2003). The prototype packages of Thai dessert for value added and tourism business promotion: case study of Thai dessert at Phetchaburi province Bangkok: Silpakorn University.

Yupadee, S.,) 2001). Human being and environment .Bangkok: Pisit, Inc. 